\title{
STUDY OF THE DECENTRALISATION PROCESS - EXAMPLES OF SUCCESSFUL PRACTICES BY SECTOR IN THE REPUBLIC OF TURKEY
}

\author{
Hasan Azis \\ Asst. Prof. Ph.D. Burgas Free University, Burgas, Bulgaria, \\ hasan.azis@gmail.com
}

\begin{abstract}
In this article are published results of a study conducted in the Republic of Turkey on the decentralisation process in five sectors: Education, Social Activities, Culture, Security and Public Administration. A questionnaire has been prepared, which included issues related to the rating of the decentralisation in the Republic of Turkey and the attitudes of the administration towards the process. The opinion of 224 people from the administration and management sector was studied. Based on the results obtained, the degree of successful integration of the decentralisation process is assessed as a form of local self-government with a clear expression of individual characteristics in the five sectors studied. Dependence of the success rate of the decentralisation process on the type of the particular sector was analytically determined. The results outline the difficulties in the decentralisation process in individual sectors and suggest ways to overcome them.
\end{abstract}

Keywords: Local authority, central government, decentralisation, local self-government, administration, attitudes, competences.

\section{INTRODUCTION}

The study of the decentralisation process in the Republic of Turkey was conducted in five key sectors for the social and economic development of the country, namely: Education, Social Activities, Culture, Security and Public Administration. The study covers ongoing work on these five sectors of engaged personnel in the state and municipal administration. In the analysis of the results studied, important recommendations are specified for improving the activity of the five sectors studied in the Republic of Turkey, in order to achieve more successful integration of the decentralised form of governance. The most important ones are:

- To conduct more training and qualification courses, to stimulate state and municipal administration to achieve better personal competencies;

- To increase the capacity and responsibility of local authorities to formulate and implement municipal policies;

- To increase the capacity and responsibility of the regional administration to implement policy and ensure compliance between national and local interests;

- To increase the efficiency of allocating resources and powers based on equal dialogue between central and local authorities. 


\section{COMPARATIVE ANALYSIS OF DECENTRALIZATION AND CENTRALIZATION PROCESSES}

Decentralization is a process of providing responsibility for the implementation of certain rights and functions of local authorities, whereby the latter are independent (within the legal limits) from the state authority in terms of their ability to solve problems in the respective fields. This means that formally the state is not responsible to citizens for the quality and efficiency of the services provided to the population, as well as for the way in which problems are solved. Of course, the state has regulated the common legal framework, standards and guarantees of equality and fairness. In this sense, decentralization should be regarded as 'part of a comprehensive and consistently realized process of transformation of the state and of civil society itself'. In such an aspect, decentralisation is basically directly associated with the improvement of territorial governance and the strengthening of self-government in territorial communities. Combining centralisation and decentralisation is an important principle in determining the model of local government (Georgiev, 2008a; Petkova, 2008b; Petrova, Petrov, 2020a).

Centralisation is most often defined as a process in which the state seizes the powers of local authorities and thus focuses control of decision-making and allocation of resources at the central level. Characteristic of this process is the "monopolization of an activity" and "centralisation is also a "form of administration". Often, the motives for seizing the powers of local authorities are "noble", but are always detrimental or not beneficial to individual administrative-territorial units. The most frequently emphasized arguments relate to the willingness and commitment of the state:

- To better satisfy the needs of local communities;

- To provide a variety of quality services;

- To manage resources in deficit settings;

- To protect the public interest or to improve control and fight against corruption, racketeering and various forms of criminal activity.

\section{DESCRIPTION OF THE METHODOLOGY USED FOR STUDYING THE DECENTRALISATION PROCESS BY RESULTS OF EXAMPLES OF SUCCESSFUL PRACTICES BY SECTORS}

By applying the selected methodology for conducting the study, the following specific tasks related to the analysis and justification of the main conclusions in this study are supposed to be solved:

- Analysis and rating of the current administrative-territorial structure of the country and the powers of the main administrative-territorial units - districts and municipalities and their bodies, to actively contribute to the strengthening of territorial governance;

- Outline the essence and role of decentralisation and review of the development of the process in the country. The importance of the Decentralisation Strategy and the Programme for its implementation for enhancing the administrative and programming capacity of regions and municipalities;

- Overview of the latest changes in EU policies, the National Strategic Reference Framework and the draft operational programmes, the mechanisms for coordination and management of assistance under the European Union Funds and highlighting of the possible range of projects under which municipalities and the areas may receive funding from them;

- Identification of restrictions for further development of the capacity of districts and municipalities;

- Study of the impact of the decentralisation process on the capacity of districts and municipalities for effective and efficient use of European Union funds and justification of measures to overcome the restrictions by accelerating the decentralisation process.

\section{RESULTS OF THE STUDY OF THE EFFECT OF THE SUCCESSFUL IMPLEMENTATION OF THE DECENTRALISATION PROCESS BY SECTORS}

Prerequisites for the development of local autonomy are clearly expressed in the Republic of Turkey. They are characterized by territorial, regulatory, institutional, financial, planning and personnel autonomy. The specific definition of these forms of autonomy highlights the following features of the types listed:

- Territorial autonomy includes the right to exercise public authority over the actual distinct own territory; 
- Institutional autonomy presupposes the formation of independent local authorities that have independent capacity, insofar as the law and the legal norms do not provide for anything else;

- The regulatory autonomy includes the right of local authorities to issue regulatory acts for the respective territory and population (so-called local law, including local regulations, ordinances, instructions, orders, etc.);

- Personnel authority suggesting local authorities to motivate professional relations, to recruit employees and workers, to set specific standards for employee positions, for the payment and provision of assistants within the law;

- Financial autonomy - local authorities have the right to prepare their own budget and have a certain tax autonomy, including collection of certain taxes and fees within the law;

- Planning authority, within which they plan the development of the territory and the local economy, establish and build their funds and infrastructure and take care of the development of sites of social infrastructure.

The participants in the study assessed the successful implementation of the decentralisation process in five sectors: Education, Social Activities, Culture, Security and Public Administration (Table 1).

Table 1. Percentage distribution of answers to questions about the success of the decentralisation process by sector

\begin{tabular}{|c|c|c|c|c|c|}
\hline $\begin{array}{l}\text { Regardless of th } \\
\text { process in the fo }\end{array}$ & $\begin{array}{l}\text { he answers t } \\
\text { ollowing sec }\end{array}$ & previous & tions, how & uld you ass & decentralisatior \\
\hline & Education & $\begin{array}{l}\text { Social } \\
\text { activities }\end{array}$ & Culture & Security & $\begin{array}{l}\text { Public } \\
\text { administration }\end{array}$ \\
\hline $\begin{array}{l}\text { Completely } \\
\text { successful }\end{array}$ & $8.9 \%$ & $6.3 \%$ & $7.1 \%$ & $8.4 \%$ & $5.4 \%$ \\
\hline $\begin{array}{l}\text { Somewhat } \\
\text { successful }\end{array}$ & $44.2 \%$ & $38.8 \%$ & $30.4 \%$ & $27.6 \%$ & $44.2 \%$ \\
\hline $\begin{array}{l}\text { Neither } \\
\text { successful nor } \\
\text { unsuccessful }\end{array}$ & $22.8 \%$ & $26.8 \%$ & $40.8 \%$ & $31.8 \%$ & $27.2 \%$ \\
\hline $\begin{array}{l}\text { Somewhat } \\
\text { unsuccessful }\end{array}$ & $9.8 \%$ & $16.5 \%$ & $10.8 \%$ & $16.8 \%$ & $11.6 \%$ \\
\hline $\begin{array}{l}\text { Completely } \\
\text { unsuccessful }\end{array}$ & $12.1 \%$ & $7.6 \%$ & $8.9 \%$ & $15.4 \%$ & $6.7 \%$ \\
\hline Total & 100.0 & 100.0 & 100.0 & 100.0 & 100.0 \\
\hline
\end{tabular}

It became clear from the table that there was an imbalance and a larger percentage of the survey participants gave a negative rating of a completely unsuccessful process compared to those who considered decentralisation by sectors to be an entirely successful process. In such results, we believe that it is not correct to write about sectors with the most successful decentralisation (Buzov, 1992; Bankova, Dimitrov. 2012; Petkova - Georgieva, 2018; Petrova, Petrov, 2020c).

On the other hand, it is necessary to compare the estimates of the decentralisation process between individual sectors and to verify the significance of the differences in success in the application of the decentralisation process, and a t-test comparison in pairs has been applied, where each sector is compared with the others, thus also subject to verification is our assumption of unevenness in the decentralisation process and presence of significant differences between sectors (Kanev, 2006; Bankova, 2014).

There is a significant difference between decentralisation in the Education sector $(M=2.73, S D=1.15$ and decentralisation in Sector Security $(M=3.03, S D=1.18)$ and); $t(214)=-3.67, p=0$." This result proved that decentralisation in the Security sector significantly lags behind decentralisation in the Education sector. The data obtained showed a significant difference between decentralisation in the Social Activities sector $(M=2.79, S D=1.05)$ and Sector Security $(M=3.04, S D=1.18) ; t(213)=-3.11, p=0.002$.

The results also showed a significant difference between decentralisation in the Culture sector $(M=2.82$, $S D=1.02)$ and decentralisation in Sector Security $(M=3.03, S D=1.19) ; t(211)=-3.11, p=0.002$. 
There is also a significant difference between decentralisation in Sector Security $(M=3.03, S D=1.17)$ and Public Administration ( $\mathrm{M}=2.69, \mathrm{SD}=1.001)$; $\mathrm{t}(212)=4.37, \mathrm{p}=0$.

The overall evaluation of the pooled statements that relate to the success of the decentralisation process by sector is 2.78 . This value placed in the rating scale is located between "Somewhat successful" and "Neither successful nor unsuccessful".

Based on the results obtained, it can be argued that the assessment of the success of the decentralization process as a whole gravitates around the middle of the scale and is rather neutral, with a slight predominance of negative assessments over positive ones. It can be argued that the success of the decentralisation process depends on the individual sector.

Plot 1. Assessment of the success of the decentralisation process in different sectors

Assessment of the decentralization process by sectors

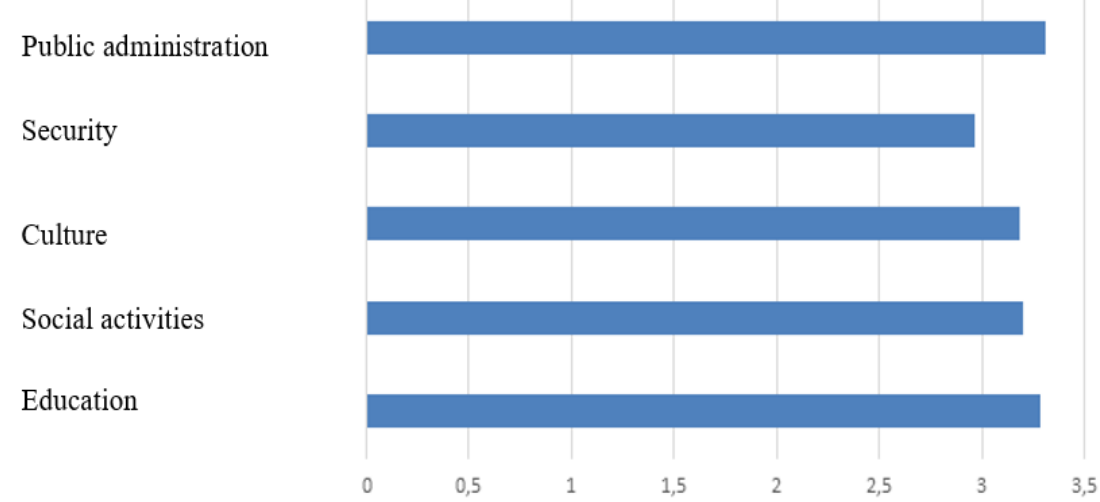

Note: For better illustration of the results obtained, the assessment scale of statements has been reversed and therefore higher values also mean a higher score. The plot is made on the basis of averages.

\section{ASSESSMENT OF THE COMPETENCES AND CAPACITY OF THE ADMINISTRATION}

When familiarizing with the assessment of the capacity of the administration, the overwhelmingly positive, high score was observed, with $57.10 \%$ of the study participants having given "rather high" and "very high" scores. Those who gave a negative, low score were $8.10 \%$ of the sample.

Plot 2. Assessment of the capacity of the administration

If you need to generally assess the capacity (knowledge, preparedness, skills, willingness for development) of the members of the administration in which you work, what would be your assessment?

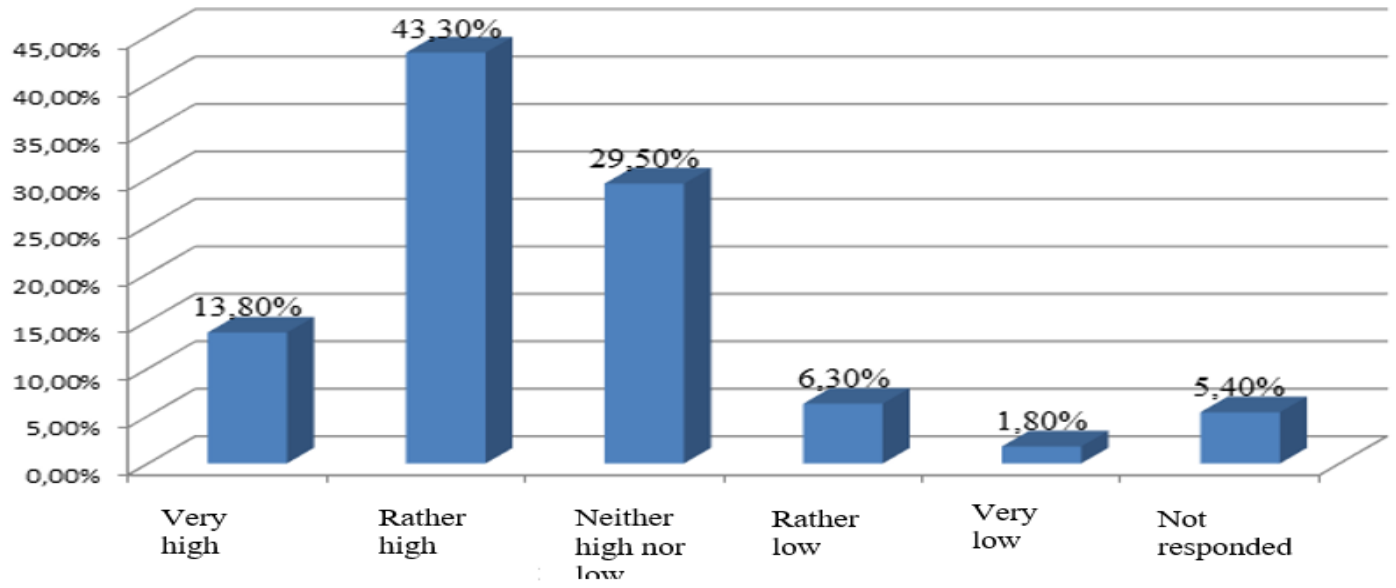

Another important aspect of the methodology that deeply reflects the qualification as such an important 
factor in decentralisation, is the need for additional training. Study participants assessed the importance of additional training in nine directions. The results are presented in Plot 3

Plot 3

What type of additional training or possibility to strengthen the skills and competencies would be most useful to the colleagues working around you in the administration
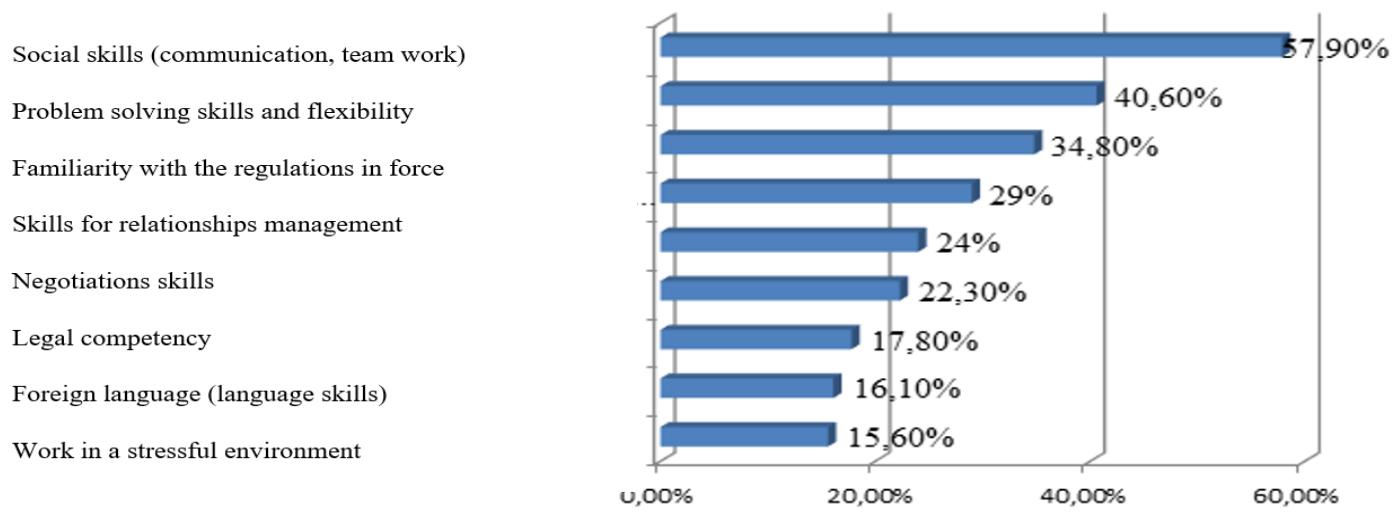

It is noteworthy that the most important criterion for successful work in administration, which at the same time requires additional training, are the human relationships - the skill, the ability of a person to communicate effectively with others and work in a team. This result can also be interpreted as a form of frustration caused by the type of workplace relationships. In the context of modern times, it can be considered surprising that digital skills are the learning for which there is the least need (Kuranov, Deliev, Penev, 2002).

Another aspect of the methodology is related to which professional fields the study participants assessed that they needed additional qualifications and training (Table 2).

Table 2. Personal additional qualification

\begin{tabular}{|l|l|}
\hline $\begin{array}{l}\text { Regardless of the answer to the previous question, if you have } \\
\text { the opportunity to choose a field where you personally would } \\
\text { like to develop some skills and competences, which of the } \\
\text { following areas w ould you choose? }\end{array}$ & $\begin{array}{l}\text { Percentage of } \\
\text { the sample }\end{array}$ \\
\hline Learning a foreign language (language skills) & $39.8 \%$ \\
\hline Social skills (communication, teamwork) & $32.1 \%$ \\
\hline Working in a stressful environment & $13 \%$ \\
\hline Problem Solving Skills and Flexibility & $32.2 \%$ \\
\hline Negotiating skills & $25 \%$ \\
\hline Skills for managing relationships and conflict situations & $21.8 \%$ \\
\hline Knowledge of the current regulations & $19.2 \%$ \\
\hline Digital skills (computer literacy) & $21.5 \%$ \\
\hline Legal competencies & $33.5 \%$ \\
\hline
\end{tabular}

The need for learning a foreign language has been identified as the most important in terms of increasing personal professional competence. Social skills are another area in which study participants feel well to develop, and this applies to their counterparts as well (Petrova, Petrov, 2020b). Again, workplace relations stand out in the foreground as an important factor in the good work of the organization. The other area in which are sought both personal development and the development of colleagues is the ability to solve problems and the flexibility. The data suggest to draw a conclusion, albeit in a hypothetical sense, that the professional stress of respondents from the Republic of Turkey is low, since the ability to work in a stressful environment is not a priority, both in personal terms and as a recommendation for the development of colleagues (Petkova, Tasheva, Petkov, 2010; Petrova, Petrov, 2020d).

The next question concerned in this study is associated with the assessment of the degree of personal 
competence and development in the areas already listed above. The personal score was checked with a five-grade scale, where 1 was "Very high" and 5 "Very low." For the sake of greater clarity in the graphical representation of the results, the scale is reversed and therefore 1 is "Very low" and 5 "Very high" respectively. It follows from the calculation of the averages that the study participants rated their competence and development in terms of social skills such as communication and teamwork (Mean=4.09, SD=0.74, i.e. the score is between "rather high" and "very high"), the skills to solve problems and flexibility (Mean=3.86, $\mathrm{SD}=0.91$ ), as well as other skills aimed at managing relationships and conflict situations (Mean=3.80, $\mathrm{SD}=0.84)$. The highest scores are in the field of human relations, and the interesting thing is that, on the one hand, the respondents rate their competence in these areas as high or very high, and on the other hand, they believe that it is precisely in these directions that it is necessary to develop and improve their skills. The lowest-rated personal competence and development refers to foreign language proficiency (Mean=2.65, $\mathrm{SD}=1,05$-between "rather low" and "neither low nor high"), and logically the respondents most want to increase their qualifications precisely in the mastery of a foreign language.

Plot 4

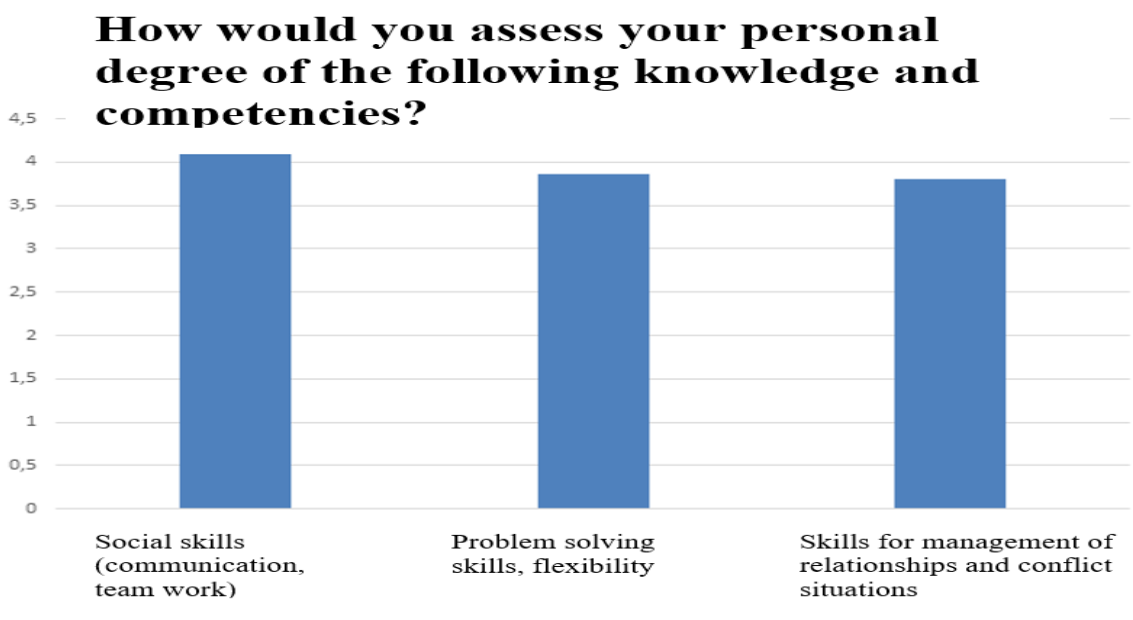

One of the most important tasks that the current research work is facing is to identify some of the factors that determine the success of the decentralisation process. After in the Bulgarian sample it has been found that the existence of working laws supporting the decentralisation process, the transparency in the work of local, regional and national authorities, as well as enhanced dialogue and partnership between central and local authorities are factors that determine the success of the decentralisation process, their influence was also verified in respondents from the Republic of Turkey, and for this purpose a regression analysis was applied, where the forecast is a dimension, drawn up from the statements listed above (Table 3).

Table 3. Estimated values of standard and non-standard ratios.

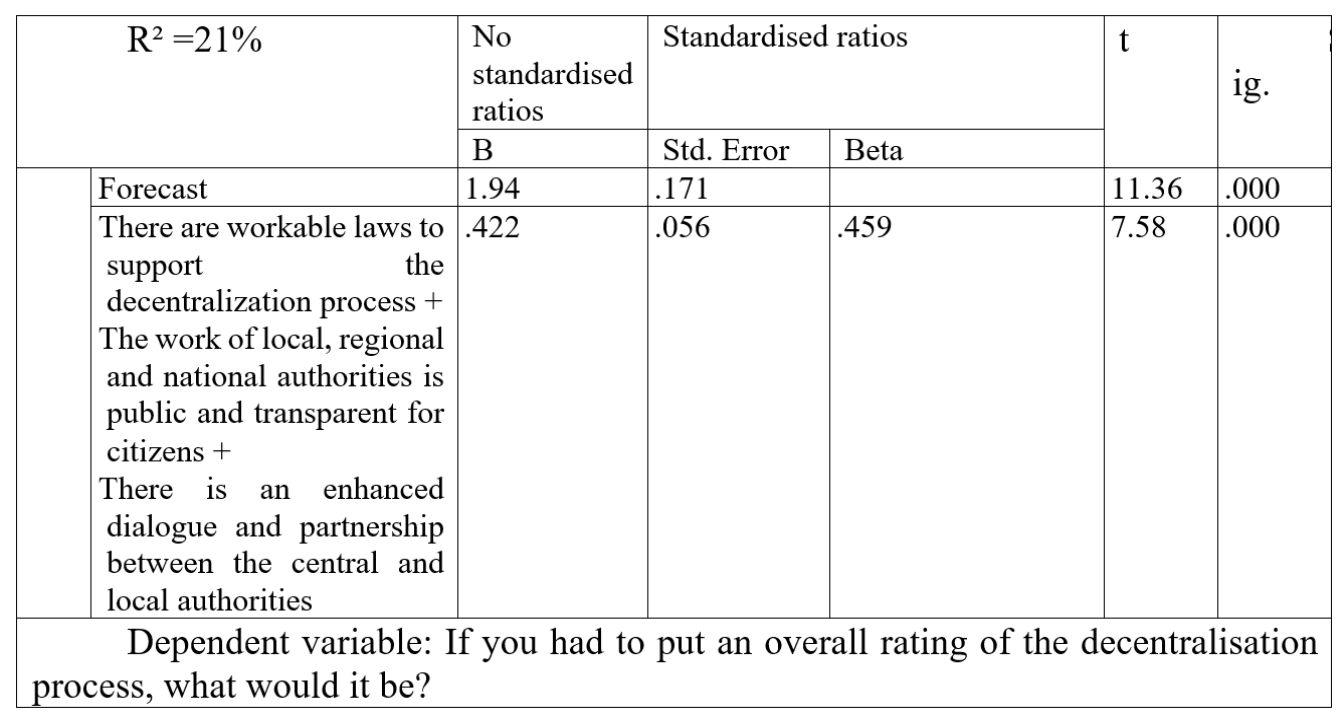

The result obtained gave us reason to predict that the presence of laws supporting the decentralisation 
process, transparency in the work of regional and national authorities, as well as dialogue and cooperation between central and local authorities will largely determine the success of the process of decentralization.

\section{CONCLUSION}

The main point in exercising power in the modern democratic state, governed by the rule of law, is the process of decentralization and allocation of competences, rights and responsibilities by the state to the lower levels of the management system hierarchy. In general, as a result of the current research, we can summarize that the decentralisation process in the studied sectors is incomplete, important reforms in the transfer of resources from central to local government have not been implemented. Another feature of the decentralisation process is that it takes place unevenly and it is implemented with different success in different sectors.

Decentralisation should not be seen solely as a process of transferring powers, responsibilities and resources from central government to a lower hierarchical level of government in a country. To a large extent, it is a process that is being deployed simultaneously on different management levels, and perhaps one of the most important for ensuring sustainability and transparency in the governance of local communities is ensuring the kind of local governance that provokes participation of local communities in making and implementing local public policies.

Strengthening the administrative capacity, considered reasonably by the European Union as a key element of Turkey's development and by a higher level of satisfaction of its population with public structures, makes us generally give preference to an improvement in the existing organization.

The consideration of the territorial model of decentralisation and the allocation of powers and functions between central and local governments is a serious problem which requires the implementation of a specific decentralisation policy covering its three aspects - political, administrative and financial.

The process of decentralisation of powers, functions and resources from central to local government is primarily seen as the permanent transfer of decision-making powers, management of local resources and control of certain public functions by the central government and its bodies to local authorities for independent and responsible implementation. In this sense, the local government and its bodies, elected directly from the population, carry out the management of the collective life in the local administrativeterritorial unit - municipality. Within the territorial entity, local government agencies have clearly outlined and legally recognized rights to conduct an independent local policy.

\section{REFERENCE LIST}

Buzov, N., (1992). Local Government and Budgetary Autonomy of Municipalities, Luren, Sofia, 1992

Georgiev, L., (2008a). Decentralisation — understood and made in journal of Public Administration, Book 2, Sofia, 2008

Kanev, D., (2006). Management and Communications in Politics, Friedrich Elbert Foundation, Sofia, 2006

Kuranov, C., Deliev, I., Penev, P., (2002). Problems of decentralisation in local government in the Republic of Bulgaria, Friedrich Elbert Foundation, Sofia, 2002 FLGR, Local Government and Young People, or why participate in local government, FLGR, Sofia, 1998 FLGR, Building Vision and Strategic Community planning, FLGM, Sofia, 2000 Stanev, H., Y. Spiridonova, A. Dzildzhov, Decentralisation and its impact on the opportunities of municipalities and districts for absorption of funds from the European Union.

Bankova, I. T., S. Dimitrov. (2012). Characteristics and some problems of Afghanistan's public administration. Tribal agreements - an alternative supporting establishment of modern public administration, The 20th NISPAcee Annual Conference 'Public Administration East and West: Twenty Years of Development', May 23 - 26, 2012, Ohrid, Republic of Macedonia (FYR Macedonia)", ISBN 978-80-89013-63-0

Bankova, I. (2014). Administrative Conflicts in Bulgarian Regional Development Policy - Current, Situation, Trends, Possible Solutions. Regionalisation and Regional Policy in Central and Eastern Europe. Book Selectet Riversed Papers from the 21st NISPAcee Annual Conference 'Public Administration Of The Future', 16-18 May 2013. Belgrade, Serbia. 2014. ISBN 978-80-89013-73-9. p.305-317. 
Petkova - Georgieva, S., (2018). Basic Problems to Solve in Strategic Controlling Implementation. // annual of University “prof. dr. Assen Zlatarov", Burgas, 2018, pp. 71 - 77, v. XLVII (2), ISSN 2603-3976

Petkova, S., Tasheva, Y., Petkov, P. (2010). Classification and possibilities of management of primary energy sources. // Oxidation Communications, 2010, 33 (2), pp. 462 - 469, ISSN 0209-4541

Petkova, S. (2008b). Balanced scorecard as instrument of strategic controlling. // Forum Gesundheit und Soziales, Beitrage aus Lehre, Forschung und Praxis der Studiengange der Evangelischen Fachhochschule, Berlin, 2008, Heft 6, pp. 60 - 68, ISSN 1863-1851

Petrova Teodora, Petrov Zhivo, (2020a). Alternative Approaches for Long-Term Defence Planning, Proceedings of SOCIOINT 2020-7th International Conference on Advances in Education and Social Sciences, 20-22 January, 2020-Dubai, U.A.E., pp. 818-825, ISBN 978-605-82433-8-5

Petrova Teodora, Petrov Zhivo, (2020b). Analysis on the Leading Trends and Capabilities of UAV'S and Their Application in the European Cooperation Projects, Proceedings of SOCIOINT 2020-7th International Conference on Advances in Education and Social Sciences, 20-22 January, 2020-Dubai, U.A.E., pp. 826-833, ISBN 978-605-82433-8-5

Petrova Teodora, Petrov Zhivo, (2020c). Economic Factors in the Development and Application of UAV'S and the Fight with Wild Fires, Proceedings of SOCIOINT 2019-7th International Conference on Advances in Education and Social Sciences, 20-22 January, 2020-Dubai, U.A.E., pp. 811-817, ISBN 978-605-82433-8-5

Petrova Teodora, Petrov Zhivo, (2020d). Long Term Development Perspectives for UAV Potential, Proceedings of SOCIOINT 2019-7th International Conference on Advances in Education and Social Sciences, 20-22 January, 2020-Dubai, U.A.E., pp. 802-810, ISBN 978-605-82433-8-5 